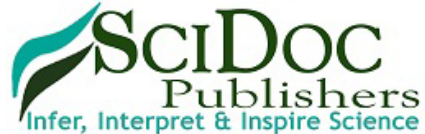

International Journal of Dentistry and Oral Science (IJDOS)

ISSN: 2377-8075

\title{
Prevalence of Osteonecrosis of the Jaw Secondary to Antiresorptive Therapy in Patients Who have Undergone Dental Surgical Procedures: A Retrospective Study
}

Review Article

\author{
Hernandez $\mathrm{MA}^{1}$, Izarra $\mathrm{A}^{2}$, Bronstein $\mathrm{D}^{3 *}$, Suzuki JB ${ }^{4}$ \\ ${ }^{1}$ Chair, Department of Periodontology Nova Southeastern University, Fort Lauderdale, FL, USA. \\ ${ }^{2}$ Department of Periodontics, Nova Southeastern University, Fort Lauderdale, FL, USA. \\ ${ }^{3}$ Associate Director of Predoctoral Periodontology, Nova Southeastern University, Fort Lauderdale, FL, USA. \\ ${ }^{4}$ Professor of Periodontology and Oral Implantology,Temple University, Philadelphia, PA. USA.
}

\section{Introduction}

Osteonecrosis is defined as "necrosis of bone due to obstruction of its blood supply" [1]. Although osteonecrosis of the jaw (ONJ) can be occur spontaneous or idiopathic, etiologic agents most often serve as modifiers for a specific case of ONJ. ONJ can result from radiation therapy to the head and neck, chronic corticosteroid use, herpes zoster virus infection in immunocompromised patients, anti-angiogenesis medications, uncontrolled infections or major trauma, and antiresorptive medications $[2,3]$.

ONJ secondary to antiresorptive medications has been previously known as Bisphoshonate-related osteonecrosis of jaw (BRONJ), Bisphosphonate - induced osteonecrosis of the jaw (BIONJ), Bisphosphonate - associated osteonecrosis of the jaw (BONJ), and Bisphosphonate - associated Osteonecrosis (BON) [4]. However, due to the introduction of non-bisphosphonate antiresorptive agents such as Denosumab and Cathepsin K inhibitors, the American Dental Association has proposed the term Antiresorptive agent-induced osteonecrosis of the jaw (ARONJ) to better encompass all medications that have been shown to increase a patients risk for developing ONJ [5, 6].

Antiresorptive medications are widely used in the prevention and treatment of metabolic bone disorders such as osteoporosis, cancer metastasis, multiple myeloma, and Paget's disease [7, 8]. The number of patients taking antiresorptive medications is projected to rise as well as the associated risks including ARONJ.

According to the American Association of Oral and Maxillofacial Surgeons (AAOMS), ARONJ is defined as exposed bone in the maxillofacial region persisting for more than eight weeks in a patient who is taking, or has taken an antiresorptive agent and has not had radiation therapy to the head and neck. The clinical presentation of ARONJ varies from case to case, although common signs and symptoms include pain, soft tissue swelling and infection, loosening of teeth, halitosis, drainage, and exposed bone $[9,10]$. ARONJ can occur spontaneously although more often precipitated by tooth extraction [11]. Other potential risk factors and comorbidities reported in the literature include diabetes mellitus [12], clinically and radiographically apparent periodontitis [13], denture wearing [9, 14], and smoking [15]. Corticosteroid use has not been consistently found to be a risk factor for ARONJ $[11,16-18]$.

Reported estimates of ONJ from oral antiresorptives range from $0.00038 \%$ to $4 \%[8,19-22]$. The highest prevalence of ARONJ in a large study population using oral bisphosphonates was approximately $0.10 \%$ [22]. The occurrence of ARONJ has been shown to be higher in cancer patients than osteopenic or osteoporotic patients. According to a systematic review the overall weighted prevalence of ARONJ in cancer patients was $6.1 \%$, ranging from $0.7 \%$ in studies with undocumented follow-up to $13.3 \%$ in studies with well documented follow-up [23]. Finally for non-bisphosphonate antiresorptive agents, the prevalence of ARONJ has been reported to as $0.061 \%$ in patients with low bone density and $2 \%$ in patients with bone metastasis $[24,25]$.

Although the reported estimates of ARONJ risk are low, clinicians are unable to determine a patient's risk for developing ARONJ prior to dental surgery procedures. The purpose of this study was to determine the prevalence of antiresorptive agentinduced osteonecrosis of the jaw (ARONJ) in patients who have taken antiresorptive medications and undergone a surgical proce-

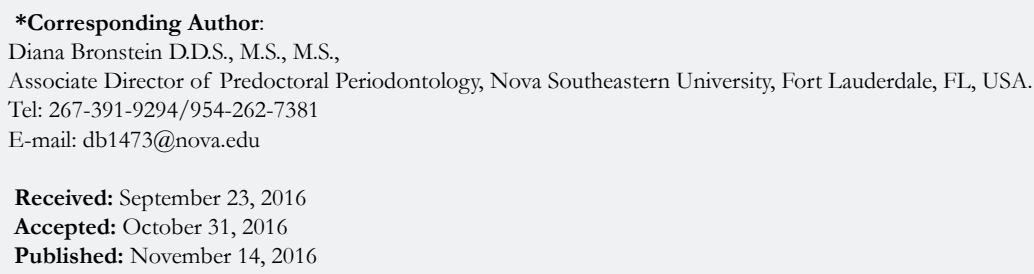


dure at NSU CDM and determine potential risk factors.

\section{Materials and Methods}

An Institutional Review Board (IRB) exemption was obtained prior to commencing the research project. The electronic health records of all Nova Southeastern University, College of Dental Medicine patients were queried for a history of antiresoprtive use. Table 1 lists the oral and parental formulations searched for on the database. Only patients with a prior history of antiresorptive use who had also undergone a dental surgery procedure were included in the study. A dental surgery procedure consisted of any procedure that involved direct bone manipulation. Patient charts were reviewed for the 1.) age and gender of patient, 2.) details of medication including name, reason for use, dose, frequency, route of administration, and length of time taking it, 3.) presence of potential risk factors such as Diabetes Mellitus, periodontitis, smoking, denture wearing, and corticosteroid use, 4.) type of surgical procedure performed on patient, 5.) whether or not the patient developed ARONJ following surgical procedure, and 6.) length of documented follow-up. The development of ARONJ was assessed using the AAOMS Staging Criteria as shown in Table 2. Patients were placed in one of the five categories in the ARONJ classification based on the clinical signs and symptoms reported on their health records at follow-ups- At Risk, Stage 0, Stage 1, Stage 2, or Stage 3.

The overall weighted prevalence of ARONJ was determined for the study population. Assessed if there were associations between ARONJ and 1.) the medication name, dose, frequency, route of administration, length of time taking the antiresorptive agent, 2.) potential risk factors such as Diabetes Mellitus, periodontitis, smoking, denture wearing, corticosteroid use, and 3.) the invasiveness of the surgical procedure. Associations were found to be statistical significance with $(\mathrm{p}<0.05)$ using the Fisher's Exact Test and the Logistic Regression Model.

\section{Results}

For the preliminary results a total of 255 patients fit the inclu-

Table 1. Antiresorptive Agents.

\begin{tabular}{|c|c|}
\hline Oral Formulations & Parenteral Formulations \\
\hline Actonel (Risedronate) & Aredia (Pamidronate) \\
\hline Atelvia (Risedronate) & Bonefos (Clodronate) \\
\hline Bonefos (Clodronate) & Boniva IV (Ibandronate) \\
\hline Bonviva (Ibandronate) & Prolia (Denosunab) \\
\hline Boniva (Ibandronate) & XGEVA (Denosunab) \\
\hline Didronel (Etidronate) & Reclast (Zoledronic acid) \\
\hline Generic Etidronate & Aclasta (Zoledronic acid) \\
\hline Fosamax (Alendronate) & Zometa (Zoledronic acid) \\
\hline Fosamax Plus (Alendronate cholecalciferol) & \\
\hline Generic Alendronate & \\
\hline Skelid (Tiludronate) & \\
\hline
\end{tabular}

Table 2. AAOMS Staging Criteria [10].

\begin{tabular}{|c|c|}
\hline Category & Criteria \\
\hline At Risk & $\begin{array}{c}\text { Clinically normal, asymptomatic patients who have received } \\
\text { antiresorptive therapy }\end{array}$ \\
\hline Stage 0 & $\begin{array}{c}\text { No clinical evidence of exposed bone, but presence of non- } \\
\text { specific symptoms or clinical and/or radiographic abnor- } \\
\text { malities }\end{array}$ \\
\hline Stage 1 & $\begin{array}{c}\text { Exposed and necrotic bone in patients who are asympto- } \\
\text { matic and have no evidence of infection }\end{array}$ \\
\hline Stage 2 & $\begin{array}{c}\text { Exposed and necrotic bone associated with pain and/or } \\
\text { signs of infection in the region of bone exposure with or } \\
\text { without purulent drainage }\end{array}$ \\
\hline $\begin{array}{c}\text { Exposed and necrotic bone in patients with pain, infection, } \\
\text { and at least one of the following: exposure and necrosis } \\
\text { extending beyond the local alveolar tissues; radiographic } \\
\text { evidence of osteolysis extending to the inferior mandibular } \\
\text { border or the maxillary sinus floor: pathologic fracture; oro- } \\
\text { antral. oro-nasal or oro-cutaneous communication }\end{array}$ \\
\hline
\end{tabular}


sion criteria and were included in the study. The mean age of the study population was $70.31 \pm 10.9$ years with the majority being female in gender 228: 27 . Of all the participants - 59\% had taken Fosamax, 20\% had taken Actonel, 13\% had taken Boniva, and 9\% comprised of patients having taken another type of antiresorptive agent. A large majority of the population (186 patients) was on antiresorptive medications to prevent and treat low bone density compared to only 10 patients that were taking the medications for either multiple myeloma or cancer metastasis. Figure 1 divides the patients depending on the documented time for taking the antiresorptive agent, with 46 patients taking AR agents for less than 1 year, 39 patients for 1 to 2 years, 33 patients for 2 to 3 years, 19 patients for 3 to 4 years, and 71 patients for over 4 years.

When examining the development of ARONJ within this population, 230 patients were categorized in the At Risk category, 19 patients in the Stage 0 category, and 6 patients in the Stage 1-3 category as shown in Figure 2. Therefore, $90.20 \%$ of patients showed no clinical signs and symptoms of ARONJ but are at an increased risk for developing ARONJ, $7.45 \%$ of patients had no clinical evidence of exposed bone but presented with nonspecific symptoms or clinical and/or radiographic abnormalities, and $2.35 \%$ of patients had ARONJ ranging from Stage 1 to 3 with varying degrees of exposed and necrotic bone, pain, and purulent drainage.

Of the patients who developed ARONJ Stage 1 to 3, 16.7\% (1 out of the 6 patients) had a history of taking Actonel, 16.7\% (1 out of the 6 patients) had a history of taking Fosamax, 16.7\% (1 out of the 6 patients) had a history of taking Boniva, 16.7\% (1 out of the 6 patients) had a history of taking both Aredia and Zometa, and $33.3 \%$ (2 out of the 6 patients) had a history of taking Zometa. Furthermore, $50 \%$ of the patients that developed ARONJ had taken IV formulations of antiresorptive agents for cancer treatment as seen in Figure 3.

The prevalence of developing ARONJ after a surgical procedure for patients with low bone density and cancer is outlined in Figure 4. Of the patients taking antiresorptive agents for low bone density, the estimated risk for developing ARONJ was 1.2 to $1.6 \%$ and of the patients taking antiresorptive agents for cancer treatment, the estimated risk for developing was 30\%.

Patients that were classified as Stage 0 did not have exposed bone that persisted for over eight weeks yet presented with signs and symptoms that were considered abnormal. There were a total of 19 patients that fell into this category and the signs included bony spicules or sequestrum alone, bony spicules or sequestrum

Figure 1. Length of Time Patients on Antiresorptive Agents Prior to Surgery.

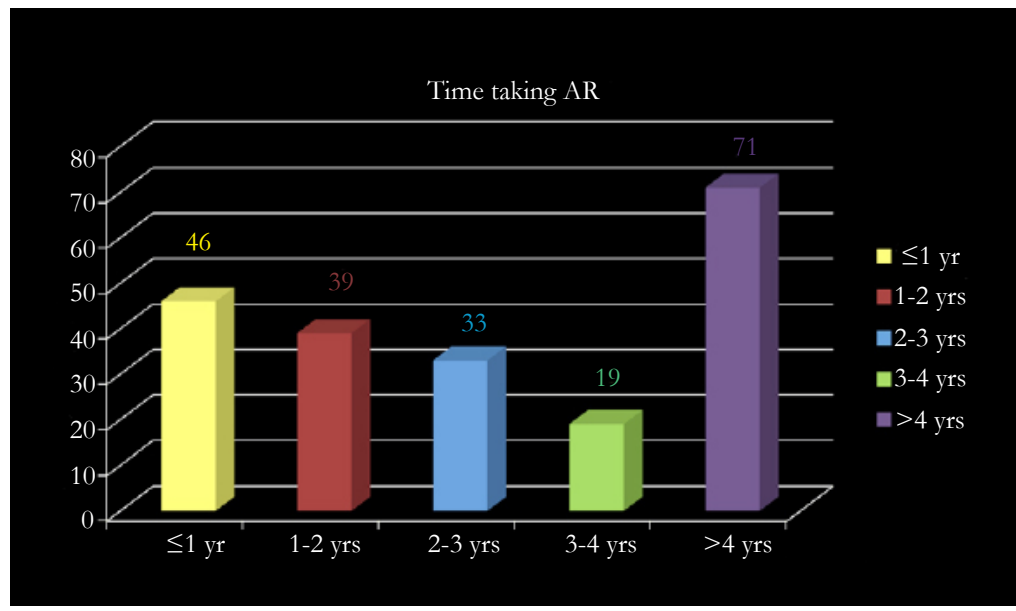

Figure 2. Prevalence of ARONJ in Study Population.

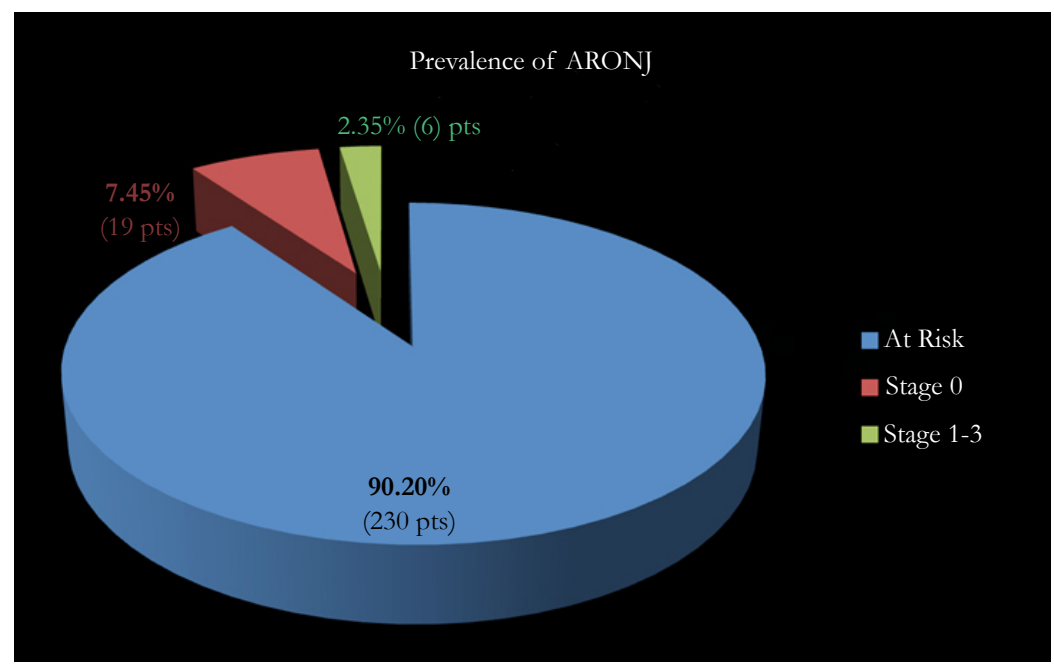


Figure 3. Medications Taken by Patients with Stage 1 to 3 ARONJ.

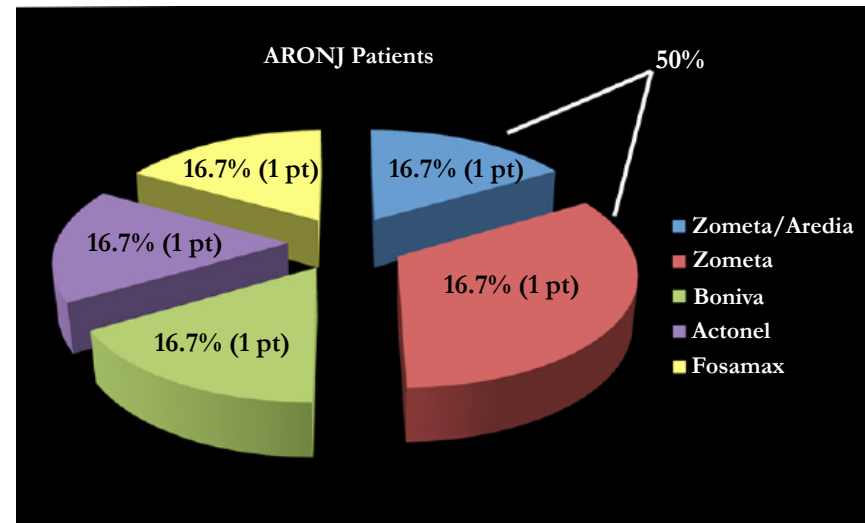

Figure 4. The Prevalence of ARONJ in Patients being Treated for Low Bone Density Versus Cancer.

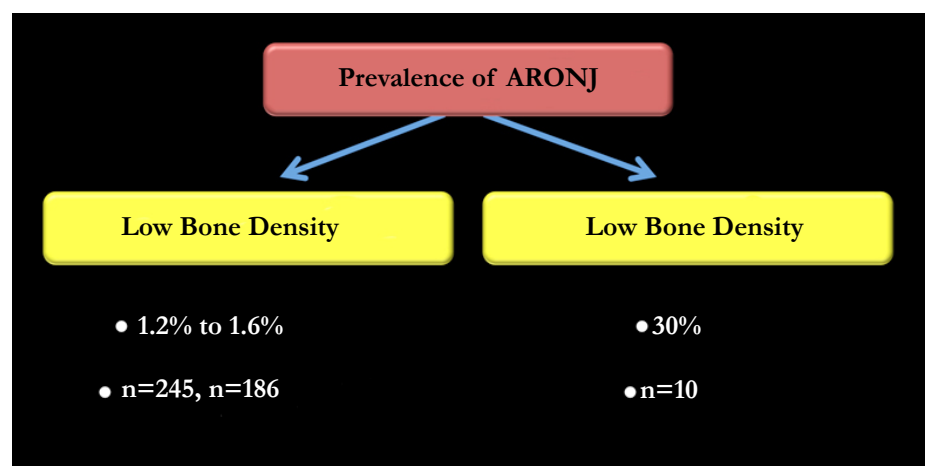

Figure 5. Unspecific Signs and Symptoms of Patients with Stage 0.

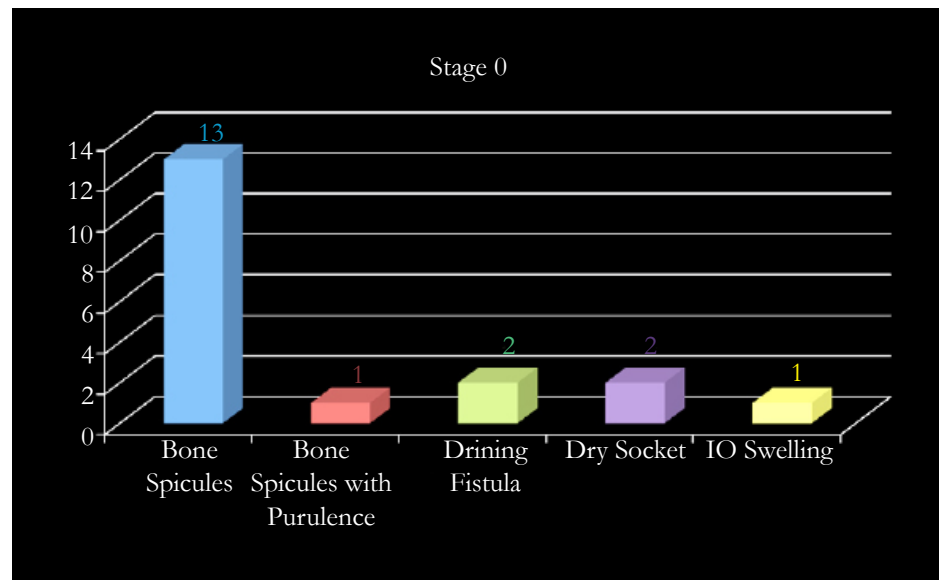

with purulence, draining fistula, dry socket, and intraoral swelling. About $74 \%$ (14 out of 19 ) of the Stage 0 cases had the presence of bony spicules or sequestrum with or without purulence as noted in Figure 5. These symptoms may or may not be related to their use of antiresorptive agents.

Of all the variables that were studied for an association with ARONJ including 1.) the medication name, dose, frequency, route of administration, length of time taking the antiresorptive agent, 2.) potential risk factors such as Diabetes Mellitus, periodontitis, smoking, denture wearing, corticosteroid use, and 3.) the invasiveness of the surgical procedure, the only variable that was found to have a statistical significant association with developing ARONJ was type of medication. The small sample size as well as missing pertinent information in incomplete records limited possible relevant associations.
The mean follow-up for the patients studied was 17.03 months with a range of 0 to 65 months.

\section{Conclusion}

Limitations of this study include its retrospective design, a relatively small sample size, incomplete medical history and records, and some patients included in the study had short term followups. With the limitations of the study, it is the first study that examines the prevalence of ARONJ after all types of surgical procedures and not solely limited to extractions. More research is needed because most of the latest guidelines proposed by the ADA are primarily based on expert opinion rather that evidence based literature. The number of patients taking these medications and the length of time patients will be on antiresorptive agents is 
expected to rise leading to an increased occurrence of ARONJ. Therefore, as dental professionals it is imperative that we become knowledgeable of these medications and risks associated to better serve and educate our patients.

\section{References}

[1]. Newman Dorland WA (2007) Dorland's Illustrated Medical Dictionary. ( $31^{\text {st }}$ edn), Saunders Elsevier, Philadelphia.

[2]. Greuter S, Schmid F, Ruhstaller T, Thuerlimann B (2008) Bevacizumabassociated osteonecrosis of the jaw. Ann Oncol. 19(12): 2091-2092.

[3]. Almazrooa SA, Woo SB (2009) Bisphosphonate and nonbisphosphonateassociated osteonecrosis of the jaw: a review. J Am Dent Assoc. 140(7): 864875.

[4]. Migliorati CA, Casiglia J, Epstein J, Jacobsen PL, Siegel MA, et al., (2005) Managing the care of patients with bisphosphonate-associated osteonecrosis: an American Acadamy of oral medicine position paper. J Am Dent Assoc. 136(12): 1658-1668

[5]. Aghaloo TL, Felsenfeld AL, Tetradis S (2010) Osteonecrosis of the Jaw in a Patient on Denosumab. J Oral Maxillofac Surg. 68(5): 959-963.

[6]. Epstein S (2006) Update of current therapeutic options for the treatment of postmenopausal osteoporosis. Clin Ther. 28(2): 151-173.

[7]. Badros A, Weikel D, Salama A, Fenton R, Ord R, et al., (2006) Osteonecrosis of the jaw in multiple myeloma patients: clinical features and risk factors. J Clin Oncol. 24(6): 945-952.

[8]. Ruggiero SL, Mehrotra B, Rosenberg TJ, Engroff SL (2004) Osteonecrosis of the jaws associated with the use of bisphosphonates: a review of 63 cases. J Oral Maxillofac Surg. 62(5): 527-534.

[9]. Ruggiero SL, Dodson TB, Assael LA, Landesberg R, Marx RE, et al., (2009) American Association of Oral and Maxillofacial Surgeons position paper on bisphosphonate-related osteonecrosis of the jaw - 2009 update. J Oral Maxillofac Surg. 67(5): 2-12.

[10]. Felsenberg D, Hoffmeister B, Amling M (2006) Bisphosphonat therapie assoziierte. Kiefernekrosen Deutsches Arzteblatt. 46: A3078-A3080.

[11]. Mavrokokki T, Cheng A, Stein B, Goss A (2007) Nature and Frequency of Bisphospnonate-Associated Osteonecrosis of the Jaws in Australia. J Oral Maxillofac Surg. 65(3): 415-423.

[12]. Cartsos VM, Zhu S, Zavras AI (2008) Bisphosponate use and the risk of adverse jaw outcomes: a medical claims study of 714,217 people. J Am Dent Assoc. 139(1): 23-40.

[13]. Sedghizadeh PP, Stanley K, Caligiuri M, Hofkes S, Lowry B, et al., (2009) Oral bisphosphonate use and the prevalence of osteonecrosis of the jaw: an institutional inquiry. J Am Dent Assoc. 140(1): 61-66.

[14]. Lo JC, O'Ryan FS, Gordon NP, Yang J, Hui RL, et al., (2010) Prevalence of osteonecrosis of the jaw in patients with oral bisphosphonate exposure. J Oral Maxillofac Surg. 68(2): 243-253.

[15]. Migliorati CA, Woo SB, Hewson I, Elting LS, Barasch A, et al., (2010) Bisphosphonate Osteonecrosis Section, Oral Care Study Group, Multinational Association of Supportive Care in Cancer (MASCC)/International Society of Oral Oncology (ISOO). A systematic review of bisphosphonate osteonecrosis (BON) in cancer. Support Care Cancer. 18(8): 1099-1106.

[16]. Lewiecki EM, Miller PD, McClung MR, Cohen SB, Liu Y, et al., (2007) Two-year treatment with denosumab (AMG 162) in a randomized phase 2 study of postmenopausal women with low BMD. J Bone Miner Res. 22(12): 1832-1841.

[17]. Stopeck AT, Lipton A, Body JJ, Fan M, Tonkin K, et al., (2010) Denosumab compared with zoledronic acid for the treatment of bone metastases in patients with advanced breast cancer: a randomized, double-blind study. J Clin Oncol. 28(35): 5132-5139.

[18]. Khamaisi M, Regev E, Yarom N, Avni B, Raz I, et al., (2007) Possible association between diabetes and bisphosphonate-related jaw osteonecrosis. J Clin Endocrinol Metabolism. 92(3): 1172-1175.

[19]. Bagan JV, Murillo J, Jimenez Y, Poveda R, Scully C, et al., (2005) Avascular jaw osteonecrosis in association with cancer chemotherapy: series of 10 cases. J Oral Pathol Med. 34(2): 120-123.

[20]. Boonyapakorn T, Schirmer I, Reichart PA, Sturm I, Massenkeil G (2008) Bisphosphonate-induced osteonecrosis of the jaws: Prospective study of 80 patients with multiple myeloma and other malignancies. Oral Oncol. 44(9): 857-869.

[21]. Vahtsevanos K, Kyrgidis A, Verrou E, Zervas K, Triaridis S, et al., (2009) Longitudinal cohort study of risk factors in cancer patients of bisphosphonate-related osteonecrosis of the jaw. J Clin Oncol. 227(32): 5356-5362.

[22]. Yarom N, Yahalom R, Shoshani Y, Hamed W, Regev E, et al., (2007) Osteonecrosis of the jaw induced by orally administered bisphosphonates: incidence, clinical features, predisposing factors and treatment outcome. Osteoporos int. 18(10): 1363- 1370.

[23]. Marx RE, Sawatari Y, Fortin M, Broumand V (2005) BisphosphonateInduced Exposed Bone (Osteonecrosis/Osteopetrosis) of the Jaws: Risk Factors, Recognition, Prevention, and Treatment. J Oral Maxillofac Surg. 63(11): 1567-1575.

[24]. Odvina CV, Zerwekh JE, Rao DS, Maalouf N, Gottschalk FA, et al., (2005) Severely suppressed bone turnover: a potential complication of alendronate therapy. J Clin Endocrinol Metabolism. 90(3): 1294-1301.

[25]. Barasch A, Cunha-Cruz J, Curro FA, Sung AH, Yin W, et al.,(2011) Risk Factors for Osteonecrosis of the Jaws: a Case-Control Study from the CONDOR Dental PBRN. J Dent Res. 90(4): 439-444. 